\title{
Effects of a mobile healthcare service provided by public health centers on practicing of health behaviors and health risk factors
}

\author{
Tae-Yon Kim ${ }^{1}$, Yun-Su Lee', Eun-Jung Yu' ${ }^{1}$, Min-Su Kim ${ }^{1}$, Sun-Young Yang ${ }^{1}$, Yang-Im Hur ${ }^{2 \S}$ and Jae-Heon Kang ${ }^{3 \varsigma}$ \\ ${ }^{1}$ Korea Health Promotion Institute, Seoul 04554, Korea \\ 2Department of Family Medicine, Seoul Paik Hospital, Inje University College of Medicine, 9, Mareunnae-ro, Jung-gu, Seoul 04551, Korea \\ ${ }^{3}$ Department of Family Medicine, Kangbuk Samsung Hospital, Sungkyunkwan University College of Medicine, Seoul 03181, Korea
}

BACKGROUND/OBJECTIVES: This study evaluated whether a mobile health (mHealth) application can instigate healthy behavioral changes and improvements in metabolic disorders in individuals with metabolic abnormalities.

SUBJECTS/METHODS: Participants were divided into an mHealth intervention group (IG), which used a mobile app for 24 weeks, and a conventional IG. All mobile apps featured activity monitors, with blood pressure and glucose monitors, and body-composition measuring devices. The two groups were compared after 24 weeks in terms of health-behavior practice rate and changes in the proportion of people with health risks, and health behaviors performed by the IG that contributed to reductions in more than one health risk factor were analyzed using multiple logistic regression.

RESULTS: Preference for low-sodium diet, reading nutritional facts, having breakfast, and performing moderate physical activity significantly increased in the mHealth IG. Furthermore, the mHealth IG showed a significant increase of eight items in the mini-dietary assessment; particularly, the items "I eat at least two types of vegetables of various colors at every meal" and "I consume dairies, such as milk, yogurt, and cheese, every day." The proportion of people with health risks, with the exception of fasting glucose, significantly decreased in the mHealth IG, while only the proportion of people with at-risk triglycerides and waist circumference of females significantly decreased in the control group. Finally, compared to those who did not show improvements of health risks, those who showed improvements of health risks in the mHealth IG had an odds ratio of 1.61 for moderate to vigorous physical activity, 1.65 for "I do not add more salt or soy sauce in my food," and 1.77 for "I remove fat in my meat before eating."

CONCLUSIONS: The findings suggest that the additional use of a community-based mHealth service through a mobile application is effective for improving health behaviors and lowering metabolic risks in Koreans.

Nutrition Research and Practice 2019;13(6):509-520; https://doi.org/10.4162/nrp.2019.13.6.509; pISSN 1976-1457 elSSN 2005-6168

Keywords: Disease management, diet, exercise, health behavior, smartphone, mobile health

\section{INTRODUCTION}

Cardiovascular diseases are the cause of approximately $20 \%$ of deaths worldwide [1]. Numerous studies have confirmed that not only the treatment of obesity, diabetes, hypertension, and hyperlipidemia with drugs, but also pre-treatment management is essential for preventing such diseases [2]. Practicing selfmanagement and maintaining a healthy lifestyle, such as healthy dietary habits and increased physical activity, are critical for managing cardiometabolic risk factors [3-5]; furthermore, such management can lower the socioeconomic costs incurred by cardiometabolic diseases [1].

One of the most important roles of health-care services is helping health-care consumers manage chronic disease and cardiometabolic risk factors by themselves, which is achieved through encouraging these consumers to practice healthy behaviors. Thus far, such healthcare services have been provided through face-to-face consultations with healthcare providers (e.g., physicians) [6]; however, with limits to the hours of care and educational materials health-care providers can dispense, providing customized education and monitoring is practically difficult [7]. Further, healthcare consumers also find it difficult to practice and maintain the lifestyle-modification behaviors that they have been taught, such as maintaining a healthy diet and physical activity, quitting smoking, drinking in moderation, and managing their weight [8]. Therefore, there is a need for a new method that can continuously provide consumers with information and feedback concerning their health behaviors.

Over the past 10 years, the field of computerized health-behavior interventions has been rapidly advancing and disseminating, primarily as a result of high levels of interest in and demand for individualized medical and health management; this interest

\footnotetext{
${ }^{\S}$ Corresponding Authors: Yang-Im Hur, Tel. 82-10-3381-2055, Fax. 82-2-2272-0908, Email. yangimhur@gmail.com Jae-Heon Kang, Tel. 82-10-3246-4697, Fax. 82-2-2001-2670, Email. fmleader@nuri.net

Received: May 18, 2018, Revised: June 25, 2018, Accepted: June 13, 2019

This is an Open Access article distributed under the terms of the Creative Commons Attribution Non-Commercial License (http://creativecommons.org/licenses/by-nc/3.0/) which permits unrestricted non-commercial use, distribution, and reproduction in any medium, provided the original work is properly cited.
} 
and demand has been caused by recent technical advances, aging population, and improved quality of life [9]. In addition to web-based health-behavior interventions, the rapid and wide penetration of cellphones over the past 10 years [10] has led to the introduction of mobile health (mHealth), and its effectiveness in terms of various health-behavior interventions has been investigated in previous studies $[10,11]$. Specifically, mHealth is defined as a "medical and public health practice supported by mobile devices, such as mobile phones, patient-monitoring devices, personal digital assistants (PDAs), and other wireless devices" [12]. Mobile-based interventions are more beneficial than conventional face-to-face consultations, as they can provide individualized health information and management methods more frequently and continuously [13]. Interventions that involve sending patient-directed short-message-service (SMS) through mobile applications (apps) help consumers achieve their behavioral goals by providing them with information about lifestyle changes, such as healthy diets or exercise, and self-management, as well as motivating educational materials or supportive messages [14]. Innovation in mHealth services may help prevent and manage cardiovascular diseases [15]. While many studies have proven that mHealth is effective for reinforcing health behaviors [16] and self-managing obesity [17], diabetes [18], hypertension [19], and cardiovascular diseases [20], there have also been contrary reports suggesting that it is ineffective in this regard [21-23]. Despite the fact that smartphone penetration in South Korea (88\%) is the highest worldwide (with the US at $75 \%$ and Europe at $80 \%$ ) [24], few studies have investigated the effects cellphone-based apps have on health management; most have only investigated ubiquitous health, such as the effects phone calls and web services [25], hospital environments $[9,26]$, and obesity management have on health [26]. Considering this, the present clinical trial aimed to evaluate whether an mHealth service app can instigate healthy behavior changes and improvements in metabolic disorders in people with metabolic abnormalities. Consequently, a 24-week study was conducted to determine whether mHealth is more effective for improving healthy behaviors and managing metabolic risk than the standard care received in public health centers.

\section{SUBJECTS AND METHODS}

\section{Study period and participants}

A total of 1,117 participants were recruited for this study (911 for the mHealth intervention group (IG) and 206 for the conventional IG). The participants who were assigned to the mHealth IG were recruited from among 1,000 individuals who had previously completed a 24-week mobile service program as part of the First-Year Public Health Center Mobile Healthcare Pilot Project, which was conducted from September 2016 to March 2017. Meanwhile, the 206 members of the conventional IG were recruited from public health centers. For this study, individuals in the conventional IG only received the face-to-face counseling services offered at public health centers, which were provided at the same time the IG was using the smartphone app.

Among those undergoing a national health examination or visiting a public health center, those who were receiving drug therapy for a chronic disease, such as hypertension or diabetes, were excluded. Those who exhibited at least one of the following five metabolic risk factors were included, according to the Adult Treatment Panel (ATP) III criteria [27] and definition of central obesity [28]: (1) fasting blood glucose (FBG) $>100 \mathrm{mg} / \mathrm{dL}$; (2) systolic blood pressure (BP) $>130 \mathrm{mmHg}$ or diastolic $\mathrm{BP}>85$ mmHg; (3) triglyceride (TG) $>150 \mathrm{mg} / \mathrm{dL}$; (4) high-density lipoprotein (HDL) cholesterol $<40 \mathrm{mg} / \mathrm{dL}$ (men) or $<50 \mathrm{mg} / \mathrm{dL}$ (women); and, (5) waist circumference (WC) $>90 \mathrm{~cm}$ (men) or $>85 \mathrm{~cm}$ (women).

Before beginning the study, informed consent was obtained from all participants based on the basic ethical principles stipulated in the Declaration of Helsinki of 1975. The study protocol was deemed exempt from examination by the clinical examination committee of Seoul Paik Hospital of Inje University (Institutional Review Board no. IIT- IIT-2016-198).

\section{Method}

Content of the mHealth service intervention group

The mHealth service provided by public health centers was designed to provide healthy lifestyle monitoring (including self-monitoring) and counseling through a mobile app over a period of 24 weeks. After receiving an explanation about the service from a public health coordinator, the mHealth IG installed the public health center mHealth app on their smartphones and registered for membership. Activity monitors were provided to all participants, along with sphygmomanometers, glucometers, and body composition measuring devices were also provided, depending on the health risk of each participant. As part of the self-management service, the participants were instructed to sync their activity monitor with the app at least five times per week, update an exercise journal at least once per week, and upload a picture of their meals once every four weeks. In addition to the baseline, mid-term (12 weeks), and final (24 weeks) examinations and consultations at public health centers, participants received weekly individualized services related to healthy lifestyles. These services were provided by professional health management teams comprising physicians, nurses, nutritionists, and physical activity experts who monitored health information online in real-time. Monthly reports were provided in order to motivate participants to continue practicing healthy lifestyle behaviors according to records. In particular, nutritionists at the public health centers conducted intensive nutritional consultations by assessing the participants' meals based on the uploaded pictures and providing advice on balanced nutritional intake. In addition, online communities for each public health center were created on the app, which facilitated consultations regarding the practice of a healthy lifestyle and the management of health risk factors. The process of the mHealth service provided by the public health centers is shown in Fig. 1.

A schematic diagram of the mHealth service platform is shown in Fig. 2.

\section{Conventional intervention group}

The conventional IG received face-to-face consultations for 24 weeks, and mid-term and final assessments were performed. These participants were recruited based on the same inclusion 


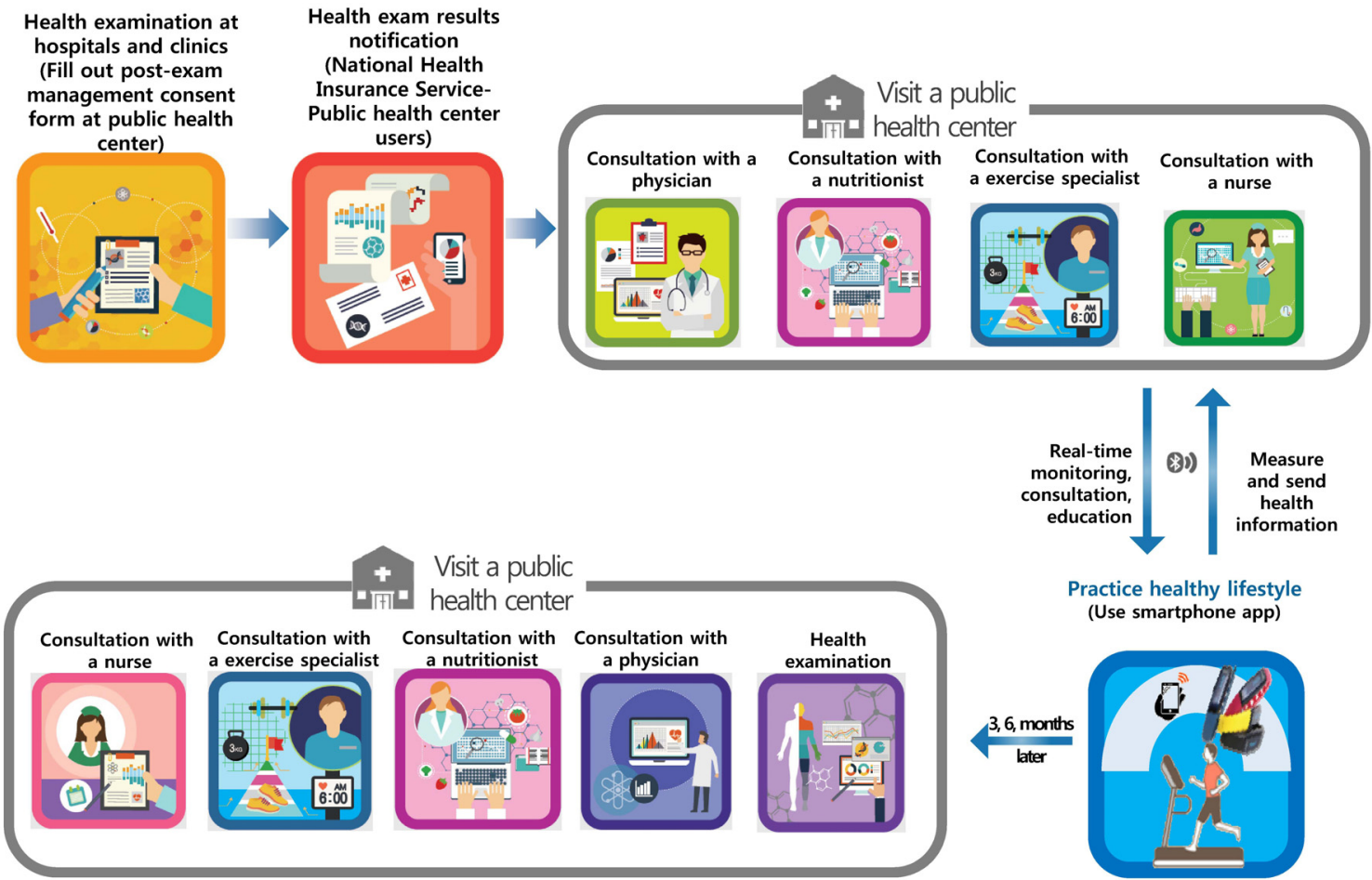

Fig. 1. Process of the mHealth service provided by public health centers.

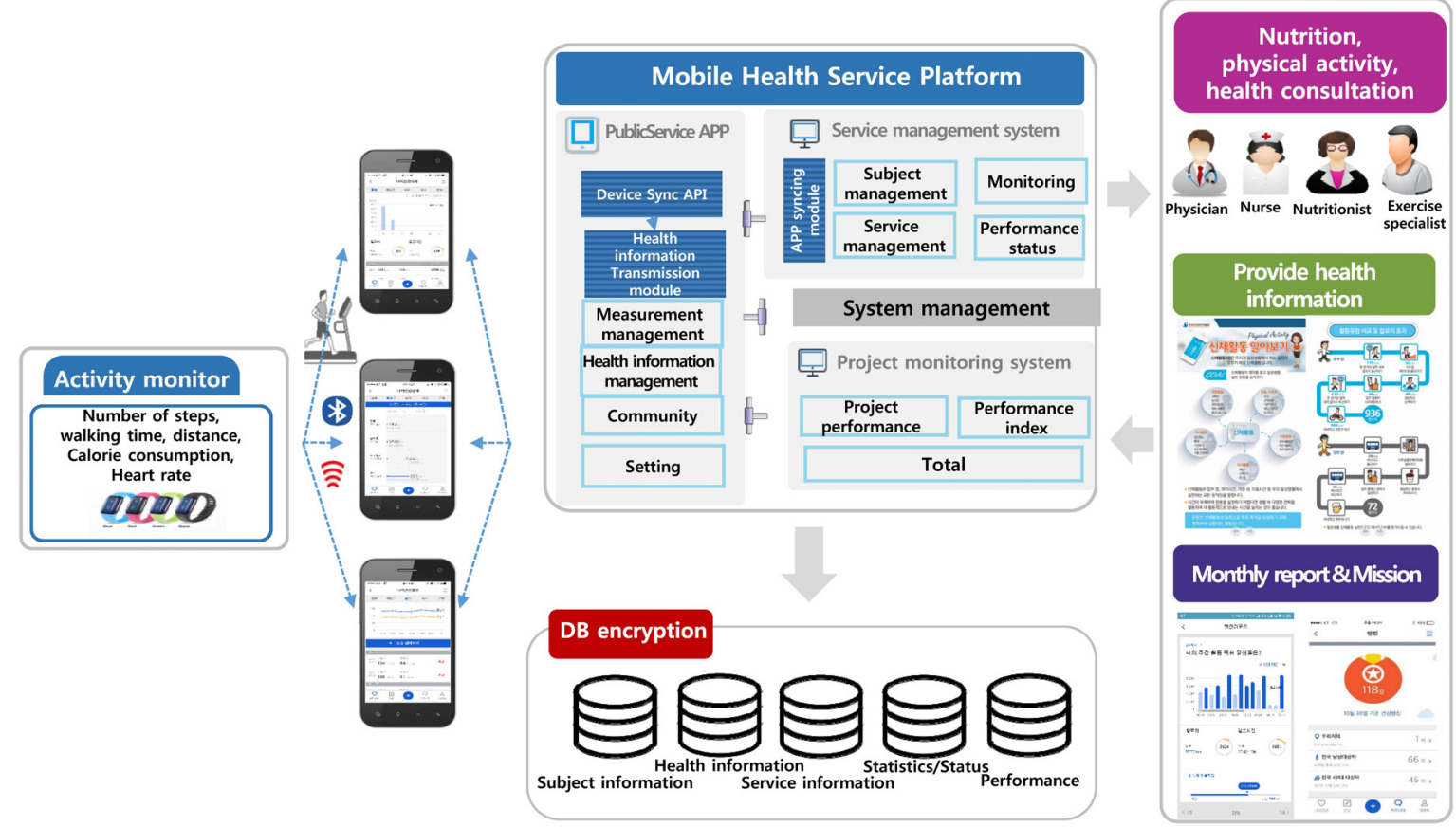

Fig. 2. Schematic diagram of the mHealth service platform.

criteria, and after classifying them according to test results, care-plans tailored to each participant's health-risk level were established. A team comprising a health manager (a health expert such as a physician or nurse), nutritionist, and certified exercise expert provided an individual or group health consultation (face-to-face; these consultations adhered to the 2011 One-Stop Health Service Consultation Manual) [29].

Anthropometric measurements, blood pressure, and blood test Prior to the pilot project, relevant personnel were trained in 
methods of performing blood tests (FBG, TG, HDL-cholesterol), anthropometric and BP measurements. Blood tests were conducted in all of the ten public health centers using the same point of care test (POCT) (LABGEOPT10, Samsung Electronics, Inc.), and BP was measured using an automated BP-measurement device for hospitals (FT-500R, Jawon Medical). The tests were conducted on three occasions: at baseline, mid-intervention (12 weeks), and post-intervention ( 24 weeks). The participants were instructed to fast for at least eight hours before visiting the public health centers for the tests.

\section{Questionnaire}

Participants' general characteristics and adherence to a healthy lifestyle were assessed using a questionnaire, which focused on education level, family size, intensity of physical activity, and smoking and dietary habits. The subjects were divided into the following age groups: 20's, 30's, 40's, $\geq 50$ 's. Meanwhile, education level was categorized as senior high ( $\leq 12$ years), college, or graduate; family size was categorized as single, two people, three people, four people, or five or more people; intensity of physical activity was categorized as almost none, a little, normal, or high; and smoking status was categorized as current smoker, ex-smoker, or non-smoker. The questionnaire was administered three times: at the baseline, mid-intervention, and post-intervention, to determine any changes in healthy lifestyle practice.

First, five basic health lifestyles were chosen: "low-sodium preference" (people who claimed to eat food with a mild or extremely low amount of salt), "read nutritional facts" (people who were knowledgeable about nutritional facts and claimed to read them when buying or choosing food products), "eat breakfast" (people who claimed to have eaten breakfast on at least five days in the previous week), "perform moderate to vigorous physical activity" (people who performed moderate physical activity, defined as at least ten minutes of activity that makes you moderately tired or short of breath, on at least five days in the previous week), and "walk" (people who walked for at least ten consecutive minutes on at least five days during the previous week).

In addition, a mini-dietary assessment was performed to assess participants' compliance to healthy diets. The questionnaire items were designed by restructuring the method presented in the 2011 One-Stop Health Service Consultation Manual [29] concerning assessing compliance to the dietary lifestyle guidelines described in the 2012 Health Exam Results Consultation Manual - Nutritional Consultation [30]. The final questionnaire comprised eight items (behaviors), and each behavior was considered practiced when it was reported as being implemented at least five times in the previous week and considered not practiced if implemented fewer than five times in the past week. For the intervention group, the questionnaire was administered through the app, while the conventional IG completed the questionnaire during their visits to the public health center on weeks 12 and 24.

\section{Data analysis}

Data from the participants who completed the 24-week program (911 in the IG and 206 in the control group) were analyzed using SAS 9.4. Results for continuous variables were presented in terms of the number of observed participants and means \pm standard deviations (SD), while those for categorical variables were presented in terms of frequency and percentage. All $P$-values were presented to the fourth decimal point, and statistical significance was set at $P>0.05$; means, standard deviations, and percentages were rounded to the nearest hundredth place. Homogeneity within the intervention and control groups was tested using Pearson's chi-square test and McNemar's test. Meanwhile, homogeneity between the intervention and control groups was tested using a 2-sample t-test for continuous variables, and Pearson's chi-square test for categorical variables. Finally, the effect of improvement in health behaviors post-intervention had on improvements in metabolic risk factors were analyzed using univariate and multiple logistic regressions.

\section{RESULTS}

\section{General characteristics of participants}

The general characteristics of the mHealth and conventional IG are presented in Table 1. The proportions of male and female participants were similar in the mHealth IG, at $49.18 \%$ and $50.82 \%$, respectively, but in the conventional IG, the proportion of female participants (65.53\%) was more than double that of the male participants (34.47\%).

Regarding highest education, the proportions of college graduates or those with higher qualifications in the mHealth and conventional IG were $71.02 \%$ and $45.15 \%$, respectively, showing that the mHealth IG was generally more educated than the conventional IG $(P<0.0001)$. In both groups, the highest number of participants lived in 4 -member families $(41.71 \%$ in the mHealth IG, 31.55\% in the conventional IG, $P=0.0392$ ).

In regard to intensity of physical activity, the difference between the two groups was not significant $(P=0.2171)$. In addition, in both groups the highest proportion of participants was non-smoking $(68.17 \%$ in the mHealth IG, $83.98 \%$ in the conventional intervention IG), and the difference between the 2 groups was significant $(P<0.0001)$.

Changes in health behaviors and dietary practice after intervention for 24 weeks

Table 2 and 3 shows the changes in health behaviors and dietary practice in the mHealth and conventional IGs after 24 weeks. The total sore of health behaviors and mini dietary assessment improved significantly only in mHealth IG $(P=0.004$, $P=0.0015$, respectively).

\section{Changes in health behaviors}

At the baseline, practice of reading nutritional facts was significantly lower in the mHealth IG (15.81\%) than in the conventional IG (25.73\%) $(P=0.0007)$, but after 24 weeks it was significantly higher in the mHealth IG (46.10\%) than in the conventional IG (28.64\%, $P<0.0001)$. Examining within each group, practice of reading nutritional facts and low-sodium preference were found to have significantly increased in the mHealth IG after 24 weeks $(P<0.0001$ and $P=0.0006$, respectively), with no significant changes in the conventional IG. 
Table 1. General characteristics of study participants

\begin{tabular}{|c|c|c|c|c|}
\hline & & Intervention group & Conventional intervention group & $P_{- \text {- }}$ \\
\hline & & $(n=911)$ & $(n=206)$ & $p$-varue \\
\hline \multirow[t]{2}{*}{$\operatorname{Sex}(n(\%))$} & Male & $448(49.18)$ & $71(34.47)$ & $<0.0001^{2)}$ \\
\hline & Female & $463(50.82)$ & $135(65.53)$ & \\
\hline Height $(\mathrm{cm})$ & & $165.50 \pm 8.47$ & $163.30 \pm 8.37$ & $0.0008^{1)}$ \\
\hline Weight (kg) & & $70.80 \pm 12.80$ & $67.44 \pm 12.41$ & $0.0006^{1)}$ \\
\hline BMI $\left(\mathrm{kg} / \mathrm{m}^{2}\right)$ & & $25.71 \pm 3.34$ & $25.18 \pm 3.48$ & $0.0393^{11}$ \\
\hline \multirow[t]{2}{*}{ WC $(\mathrm{cm})$} & Male & $92.30 \pm 7.88$ & $90.58 \pm 7.87$ & $0.0872^{11}$ \\
\hline & Female & $84.30 \pm 9.00$ & $85.17 \pm 8.35$ & $0.3190^{1)}$ \\
\hline Systolic BP (mmHg) & & $128.40 \pm 14.74$ & $124.40 \pm 15.89$ & $0.0007^{1)}$ \\
\hline Diastolic BP (mmHg) & & $83.00 \pm 10.37$ & $80.92 \pm 10.86$ & $0.0100^{1)}$ \\
\hline FBS (mg/dL) & & $103.30 \pm 12.27$ & $103.60 \pm 14.16$ & $0.7325^{1)}$ \\
\hline Triglyceride (mg/dL) & & $170.80 \pm 94.85$ & $175.50 \pm 102.00$ & $0.5273^{11}$ \\
\hline \multirow[t]{2}{*}{ HDL-cholesterol (mg/dL) } & Male & $46.80 \pm 9.86$ & $48.58 \pm 11.24$ & $0.1680^{1)}$ \\
\hline & Female & $53.73 \pm 11.42$ & $51.76 \pm 9.67$ & $0.0473^{1)}$ \\
\hline \multirow[t]{5}{*}{ Age (yrs) } & Average & $44.68 \pm 8.22$ & $44.69 \pm 8.22$ & $0.9919^{1)}$ \\
\hline & $20-29$ & $35(3.84)$ & $10(4.85)$ & $0.6768^{2)}$ \\
\hline & $30-39$ & 231 (25.36) & $52(25.24)$ & \\
\hline & $40-49$ & $340(37.32)$ & $69(33.50)$ & \\
\hline & $\geq 50^{\prime} \mathrm{s}$ & 305 (33.48) & $75(36.41)$ & \\
\hline \multirow[t]{3}{*}{ Education level (n(\%)) } & $\leq$ Senior high ( $\leq 12$ yrs $)$ & $264(28.98)$ & $113(54.85)$ & $<0.0001^{2)}$ \\
\hline & College & $556(61.03)$ & $82(39.81)$ & \\
\hline & $\geq$ Graduate & 91 (9.99) & $11(5.34)$ & \\
\hline \multirow[t]{6}{*}{ Family size (n(\%)) } & Alone & $47(5.16)$ & $7(3.40)$ & $0.0392^{2)}$ \\
\hline & 2 & $164(18.00)$ & $50(24.27)$ & \\
\hline & 3 & $213(23.38)$ & $51(24.76)$ & \\
\hline & 4 & $380(41.71)$ & $65(31.55)$ & \\
\hline & $\geq 5$ & $104(11.42)$ & $29(14.08)$ & \\
\hline & Non-response & $3(0.33)$ & $4(1.94)$ & \\
\hline \multirow[t]{5}{*}{ Intensity of physical activity $(\mathrm{n}(\%))$} & Almost none & $239(26.23)$ & $40(19.42)$ & $0.2171^{2)}$ \\
\hline & A little & $327(35.89)$ & $83(40.29)$ & \\
\hline & Normal & $242(26.56)$ & $47(22.82)$ & \\
\hline & High & $93(10.21)$ & $21(10.19)$ & \\
\hline & Non-response & $10(1.10)$ & $15(7.28)$ & \\
\hline \multirow[t]{3}{*}{ Smoking ( $(\%))$} & Non-smoker & $621(68.17)$ & $173(83.98)$ & $<0.0001^{2)}$ \\
\hline & Ex-smoker & $157(17.23)$ & $14(6.80)$ & \\
\hline & Current smoker & $133(14.60)$ & $19(9.22)$ & \\
\hline
\end{tabular}

Values are expressed as mean $\pm \mathrm{SD}$ or $\mathrm{n}(\%)$.

${ }^{1)}$ Continuous values are expressed as means and standard deviations, and $P$-values were obtained from a 2-sample t-test.

${ }^{2)}$ Nominal variables are presented as $\mathrm{n}(\%)$ and $P$-values obtained using a chi-square test.

BMI, Body Mass Index; WC, waist circumference; BP, blood pressure; FBS, fasting blood sugar; HDL cholesterol, high-density lipoprotein cholesterol.

At the baseline, the practice of eating breakfast and performing moderate physical activity was lower in the mHealth IG than in the conventional IG $(P=0.0349$ and $P=0.0129$, respectively), but there were no significant differences between the two groups after 24 weeks $(P=0.9605$ and $P=0.7449)$. Within each group, the practice of eating breakfast and performing moderate physical activity significantly increased in the mHealth IG after 24 weeks $(P<0.0001$ and $P=0.0004$, respectively), with no significant changes in the conventional IG.

The practice of walking was significantly higher in the mHealth IG $(44.35 \%)$ than in the conventional IG $(36.41 \%, P=0.0376)$ at the baseline and week 24. Finally, within each group, the practice of walking was found to have significantly increased in both groups after 24 weeks $(P<0.0001$ for the mHealth IG, $P=0.0063$ for the conventional IG).

\section{Changes in dietary practice}

It was found that, after the 24 weeks, the practice of the eight items on the mini dietary questionnaire had increased in both groups. At week 24, the practices of "I eat at least two types of vegetables of various colors at every meal" $(72.65 \%$ for the $\mathrm{mHealth}$ IG, $58.42 \%$ for the conventional IG) and "I consume dairy, such as milk, yogurt, and cheese, every day" (53.16\% for mHealth IG, 40.59\% for conventional IG) were significantly higher in the mHealth IG than in the conventional IG $(P<0.0001$ and $P=0.0012$, respectively). 
Table 2. Changes in total score of health behaviors and dietary practice after intervention for 24 weeks

\begin{tabular}{|c|c|c|c|c|}
\hline Health behaviors & & mHealth intervention group & Conventional intervention group & $P$-value ${ }^{1)}$ \\
\hline \multirow[t]{3}{*}{ Health behaviors scores } & base & $1.50(0.06)$ & $1.67(0.09)$ & 0.0533 \\
\hline & 24 weeks & $2.12(0.06)$ & $1.76(0.10)$ & 0.0002 \\
\hline & $P$-value ${ }^{2)}$ & 0.004 & 0.092 & \\
\hline \multirow[t]{3}{*}{ Mini dietary assessment scores } & base & $4.53(0.10)$ & $4.77(0.16)$ & 0.0998 \\
\hline & 24 weeks & $5.57(0.08)$ & $5.13(0.14)$ & 0.0006 \\
\hline & $P$-value ${ }^{2)}$ & 0.0015 & 0.3978 & \\
\hline
\end{tabular}

Results are presented as least square means with standard error by adjusting for sex, age, education level, family size, and smoking at baseline.

1) $P$-values obtained using generalized linear model.

2) P-values obtained using repeated measures ANOVA

mHealth: mobile health

Table 3. Changes in health behaviors and dietary practice after intervention for 24 weeks

\begin{tabular}{|c|c|c|c|c|}
\hline Health behaviors $^{3)}$ & & mHealth Intervention Group & Conventional Intervention Group & $P$-value ${ }^{11}$ \\
\hline \multirow[t]{3}{*}{ Low-sodium preference } & base & $174(19.10)$ & $37(17.96)$ & 0.7061 \\
\hline & 24 weeks & $214(23.49)$ & 37 (17.96) & 0.0860 \\
\hline & $P$-value ${ }^{2)}$ & 0.0006 & 1.0000 & \\
\hline \multirow[t]{3}{*}{ Reading nutritional facts (label) } & base & $144(15.81)$ & $53(25.73)$ & 0.0007 \\
\hline & 24 weeks & $420(46.10)$ & $59(28.64)$ & $<0.0001$ \\
\hline & $P$-value ${ }^{2)}$ & $<0.0001$ & 0.3853 & \\
\hline \multirow[t]{3}{*}{ Eating breakfast } & base & $515(56.53)$ & $133(64.56)$ & 0.0349 \\
\hline & 24 weeks & $581(63.78)$ & $131(63.59)$ & 0.9605 \\
\hline & $P$-value $e^{2)}$ & $<0.0001$ & 0.7237 & \\
\hline \multirow[t]{3}{*}{ Performing moderate physical activity } & base & 109 (11.96) & $38(18.45)$ & 0.0129 \\
\hline & 24 weeks & $155(17.01)$ & 37 (17.96) & 0.7449 \\
\hline & $P$-value ${ }^{2)}$ & 0.0004 & 0.8474 & \\
\hline \multirow[t]{3}{*}{ Walking } & base & $404(44.35)$ & $75(36.41)$ & 0.0376 \\
\hline & 24 weeks & $539(59.17)$ & $96(46.60)$ & 0.0010 \\
\hline & $P$-value $e^{2)}$ & $<0.0001$ & 0.0063 & \\
\hline \multicolumn{5}{|l|}{ Mini-dietary questionnaire ${ }^{4)}$} \\
\hline \multirow[t]{3}{*}{ I eat various grains and a lot of whole grains } & base & $543(60.13)$ & $131(64.85)$ & 0.2139 \\
\hline & 24 weeks & $664(73.53)$ & $143(70.79)$ & 0.4275 \\
\hline & $P$-value ${ }^{2)}$ & $<0.0001$ & 0.1161 & \\
\hline \multirow{3}{*}{$\begin{array}{l}\text { I eat at least } 2 \text { types of vegetables of various colors } \\
\text { at every meal }\end{array}$} & base & $524(58.03)$ & $117(57.92)$ & 0.9776 \\
\hline & 24 weeks & $656(72.65)$ & $118(58.42)$ & $<0.0001$ \\
\hline & $P$-value ${ }^{2)}$ & $<0.0001$ & 1.0000 & \\
\hline \multirow[t]{3}{*}{ I eat a variety of seasonal fruits every day } & base & $520(57.59)$ & $114(56.44)$ & 0.7651 \\
\hline & 24 weeks & $589(65.23)$ & 124 (61.39) & 0.3023 \\
\hline & $P$-value ${ }^{2)}$ & $<0.0001$ & 0.1655 & \\
\hline \multirow{3}{*}{$\begin{array}{l}\text { I consume dairy, such as milk, yogurt, and cheese, } \\
\text { every day }\end{array}$} & base & $360(39.87)$ & $80(39.60)$ & 0.9449 \\
\hline & 24 weeks & $480(53.16)$ & $82(40.59)$ & 0.0012 \\
\hline & $P$-value ${ }^{2)}$ & $<0.0001$ & 0.7728 & \\
\hline \multirow{3}{*}{$\begin{array}{l}\text { I eat a balanced diet with rice and various side } \\
\text { dishes (Korean-style meal) }\end{array}$} & base & $547(60.58)$ & $140(69.31)$ & 0.0207 \\
\hline & 24 weeks & $686(75.97)$ & $153(75.74)$ & 0.9458 \\
\hline & $P$-value ${ }^{2)}$ & $<0.0001$ & 0.0633 & \\
\hline \multirow[t]{3}{*}{ I do not add salt or soy sauce to my food } & base & $631(69.88)$ & 155 (76.73) & 0.0520 \\
\hline & 24 weeks & $748(82.83)$ & $166(82.18)$ & 0.8234 \\
\hline & $P$-value ${ }^{2)}$ & $<0.0001$ & 0.1086 & \\
\hline \multirow[t]{3}{*}{ I remove fat from my meat before eating } & base & $380(42.08)$ & $94(46.53)$ & 0.2477 \\
\hline & 24 weeks & $515(57.03)$ & 106 (52.48) & 0.2380 \\
\hline & $P$-value ${ }^{2)}$ & $<0.0001$ & 0.1151 & \\
\hline \multirow{3}{*}{$\begin{array}{l}\text { I eat fewer fried foods (including pan-fried dishes } \\
\text { and pancakes) }\end{array}$} & base & 557 (61.68) & 134 (66.34) & 0.2168 \\
\hline & 24 weeks & 715 (79.18) & 161 (79.70) & 0.8685 \\
\hline & $P$-value ${ }^{2)}$ & $<0.0001$ & 0.0002 & \\
\hline
\end{tabular}

Nominal variables are presented as $\mathrm{n}(\%)$.

1) $P$-values obtained using a chi-square test.

2) $P$-values obtained using McNemar's test.

3) Health behaviors: 911 in the mobile Health $I G$ and 206 in the conventional intervention group.

4) Mini dietary questionnaire: 903 in the mobile Health IG and 202 in the conventional intervention group.

mHealth: mobile health 
Table 4. Changes in the proportion of people with metabolic risk factors after intervention for 24 weeks

\begin{tabular}{|c|c|c|c|c|c|c|c|}
\hline & & & \multicolumn{2}{|c|}{ mHealth intervention group } & \multicolumn{2}{|c|}{ Conventional intervention group } & \multirow{2}{*}{$P$-value ${ }^{1}$} \\
\hline & & & $\mathrm{n}$ & n (\%) & $\mathrm{n}$ & n (\%) & \\
\hline \multirow[t]{3}{*}{ Systolic BP } & & base & 911 & $462(50.71)$ & 206 & $69(33.50)$ & $<0.0001$ \\
\hline & & 24 weeks & 911 & $317(34.80)$ & 206 & $71(34.47)$ & 0.9282 \\
\hline & & $P$-value ${ }^{2)}$ & \multicolumn{2}{|c|}{$<0.0001$} & \multicolumn{2}{|c|}{0.7773} & \\
\hline \multirow{3}{*}{\multicolumn{2}{|c|}{ Diastolic BP }} & base & 911 & 407 (44.68) & 206 & $73(35.44)$ & 0.0156 \\
\hline & & 24 weeks & 911 & $310(34.03)$ & 206 & $63(30.58)$ & 0.3436 \\
\hline & & $P$-value ${ }^{2)}$ & \multicolumn{2}{|c|}{$<0.0001$} & \multicolumn{2}{|c|}{0.2184} & \\
\hline \multirow[t]{3}{*}{ FBS } & & base & 911 & $465(51.04)$ & 206 & $113(54.85)$ & 0.3228 \\
\hline & & 24 weeks & 911 & $539(59.17)$ & 206 & $126(61.17)$ & 0.5975 \\
\hline & & $P$-value ${ }^{2)}$ & \multicolumn{2}{|c|}{$<0.0001$} & \multicolumn{2}{|c|}{0.1069} & \\
\hline \multirow[t]{3}{*}{ Triglyceride } & & base & 911 & 477 (52.36) & 206 & 106 (51.46) & 0.8146 \\
\hline & & 24 weeks & 911 & 386 (42.37) & 206 & $88(42.72)$ & 0.9274 \\
\hline & & $P$-value ${ }^{2)}$ & \multicolumn{2}{|c|}{$<0.0001$} & \multicolumn{2}{|c|}{0.0201} & \\
\hline \multirow[t]{6}{*}{ WC } & Male & base & 448 & $292(65.18)$ & 71 & $32(45.07)$ & 0.0012 \\
\hline & & 24 weeks & 448 & $230(51.34)$ & 71 & $30(42.25)$ & 0.1549 \\
\hline & & $P$-value ${ }^{2)}$ & \multicolumn{2}{|c|}{$<0.0001$} & \multicolumn{2}{|c|}{0.6171} & \\
\hline & Female & base & 463 & $244(52.70)$ & 135 & $70(51.85)$ & 0.8622 \\
\hline & & 24 weeks & 463 & $166(35.85)$ & 135 & $50(37.04)$ & 0.8011 \\
\hline & & $P$-value ${ }^{2)}$ & & & & & \\
\hline \multirow[t]{6}{*}{ HDL-cholesterol } & Male & base & 448 & 93 (20.76) & 71 & 17 (23.94) & 0.5418 \\
\hline & & 24 weeks & 448 & $69(15.40)$ & 71 & $13(18.31)$ & 0.5325 \\
\hline & & $P$-value ${ }^{2)}$ & \multicolumn{2}{|c|}{0.0133} & \multicolumn{2}{|c|}{0.3173} & \\
\hline & Female & base & 463 & 201 (43.41) & 135 & $54(40.00)$ & 0.4805 \\
\hline & & 24 weeks & 463 & 153 (33.05) & 135 & $59(43.70)$ & 0.0227 \\
\hline & & $P$-value ${ }^{2)}$ & \multicolumn{2}{|c|}{$<0.0001$} & \multicolumn{2}{|c|}{0.4349} & \\
\hline
\end{tabular}

Nominal variables are presented as $\mathrm{n}(\%)$.

1) $P$-values obtained using chi-square tests

2) P-values obtained from McNemar's test.

WC, waist circumference; BP, blood pressure; FBS, fasting blood sugar; HDL cholesterol, high-density lipoprotein cholesterol; mHealth, mobile health.

Definition of metabolic risk factors: systolic BP > $130 \mathrm{mmHg}$; diastolic BP > $85 \mathrm{mmHg}$; FBS $>100 \mathrm{mg} / \mathrm{dL}$; waist circumference (WC) >90 cm (men) or > $85 \mathrm{~cm}$ (women); triglyceride $>150 \mathrm{mg} / \mathrm{dL}$; and $\mathrm{HDL}$-cholesterol $<40 \mathrm{mg} / \mathrm{dL}$ (men) or $<50 \mathrm{mg} / \mathrm{dL}$ (women).

Changes in the proportion of people with metabolic risk factors after intervention for 24 weeks

Changes in the proportion of people with metabolic risk factors after 24 weeks are shown in Table 4. For the mHealth IG, the proportion of people with all metabolic risk factors, except FBG, significantly decreased. Only the proportion of people with at-risk TG and WC of females significantly decreased in the conventional IG. The proportion of people with at-risk FBG increased in both groups after 24 weeks. This change was significant in the mHealth IG $(P<0.0001)$ but not in the conventional IG.

At the baseline, the proportion of people with at-risk systolic $\mathrm{BP}$, diastolic $\mathrm{BP}$, and $\mathrm{WC}$ in males was significantly higher in the mHealth IG than in the conventional IG, but the two groups did not significantly differ at week 24 . On the other hand, the proportion of female participants with at-risk HDL-cholesterol did not significantly differ between the 2 groups at the baseline (43.41\% in the mHealth IG, $40.00 \%$ in the conventional IG, $P=0.4805)$, but at week 24 , it was significantly lower in the mHealth IG (33.05\%) than in the conventional IG $(43.70 \%)$ $(P=0.0227)$.

Factors that contribute to the reduction of metabolic risk factors Multivariate logistic regression was performed to identify the factors that contributed to lowering at least one of the five
Table 5. Factors that contribute to reducing at least one of the five baseline metabolic risk factors in mobile health intervention group for 24 weeks

\begin{tabular}{lccc}
\hline & Odds ratio $^{1)}$ & $95 \% \mathrm{Cl}^{2)}$ & $P$-value \\
\hline Sex & 1 & & \\
Male & 1.37 & $(1.05-1.80)$ & $0.0210^{*}$
\end{tabular}

Performing moderate physical activity more than 5 days a week Non-practicing

Practicing $1.61 \quad(1.23-2.10) \quad 0.0006^{* * *}$

I eat at least 2 types of vegetables of various colors at every meal

$\begin{array}{llll}\text { Non-practicing } & 1 & & \\ \text { Practicing } & 1.27 & (0.93-1.75) & 0.1370\end{array}$

I do not add salt or soy sauce to my food

Non-practicing 1

$\begin{array}{llll}\text { Practicing } & 1.65 & (1.19-2.28) & 0.0029^{* *}\end{array}$

I remove fat from my meat before eating

Non-practicing 1

$\begin{array}{llll}\text { Practicing } & 1.77 & (1.26-2.48) & 0.0009^{* * *}\end{array}$

${ }^{1)}$ Results are presented as adjusted odds ratios with $95 \% \mathrm{Cl}$ obtained using multiple logistic regression analysis and were adjusted for factors that were determined through univariate logistic regression to be significant (Gender, moderate to vigorous physical activity, "I eat at least 2 types of vegetables of various colors at every meal," "I do not add salt or soy sauce to my food," and "I remove fat from my meat before eating,")

2) * $P<0.05$, ${ }^{* *} P<0.01,{ }^{* \star *} P<0.001$

Cl: Confidence interval 
baseline metabolic risk factors (systolic/diastolic BP, FBG, TG, WC, HDL-cholesterol) after the 24-week intervention in the mHealth IG. The results are shown in Table 5.

Gender, moderate to vigorous physical activity, "I eat at least 2 types of vegetables of various colors at every meal," "I do not add salt or soy sauce to my food," and "I remove fat from my meat before eating" were the factors with significant effects in terms of lowering at least one metabolic risk factors after univariate logistic regression analysis. The effect of each factors was analyzed and adjusted for other factors by using multiple logistic regression. The results showed that one or more metabolic risk factors had improved 1.37 times (1.05-1.80) more in women than men. Compared to the participants who did not practice healthy lifestyles, those who practice healthy lifestyles had improvement in metabolic risk factors. The odds ratios were: 1.61 for moderate physical activity $(1.23-2.10, P=$ $0.0006), 1.65$ for "I do not add salt or soy sauce to my food" (1.19-2.28, $P=0.0029)$, and 1.77 for "I remove fat from my meat before eating" (1.26-2.48, $P=0.0009)$.

\section{DISCUSSION}

This study aimed to determine whether the use of mHealth services through a mobile app is more effective than face-toface consultations for improving health behaviors and health status in Koreans with metabolic risks. Consequently, the mHealth service was indeed found to be more effective than conventional face-to-face consultations in this regard. Performing moderate physical activity, eating at least two types of vegetables at every meal, not adding salt or soy sauce to food, and removing fat from meat before eating were particularly helpful factors of improving metabolic abnormalities.

Several studies have confirmed that mHealth services effectively change behaviors, such as those relating to physical activity and dietary habits [31]. According to Payne and colleague's [11] systematic review of mobile apps used in health-behavior interventions, mobile apps are useful for changing health behaviors and are acceptable tools for consumers. In the present study, an app was used for not only recording food and/or exercise activities, but also investigating changes in knowledge and behaviors.

The assessment of health behaviors using a five-item questionnaire (three items for diet and two items for exercise) and of healthy dietary practice using an eight-item questionnaire showed that for improving behavior changes and dietary habits, the mobile app service was more effective than face-toface consultations. Whereas the conventional IG only received in-person consultation, the mobile app featured behavior change techniques, such as motivational messages, goal-setting, tailored health education/advice, self-monitoring, performance feedback, gamification, and awards and rewards. In a metaanalysis by Kelly et al. [32], telehealth-delivered dietary interventions targeting whole food and/or dietary patterns were found to improve diet quality, fruit and vegetable intake, and sodium intake when compared to control groups. Further, a recent systematic review also reported that mobile apps are effective for improving diet, physical activity, and sedentary behavior and, consequently, preventing non-communicable diseases
(NCDs) [14]. Maintaining good exercise and lifestyle habits is essential for managing metabolic risk [33]. Thus, this app can be considered useful for increasing knowledge about exercise and nutrition and for promoting behavioral changes for managing and preventing metabolic diseases.

Numerous longitudinal studies and RCTs have proven that mHealth services can lower metabolic risks by promoting lifestyle changes, such as improved exercise and diet [14]. Furthermore, previous studies have reported that using other intervention strategies in addition to mobile app interventions leads to a greater and longer effect than when using mobile app interventions alone [14]. Similarly, our study also found that health behaviors and parameters were more improved in the group of people who used the mobile app in conjunction with conventional face-to-face counseling. While the conventional IG only showed significant decreases in the proportion of people with TG abnormalities and the proportion of females with at-risk WC, the mHealth IG showed a significant reduction in all metabolic abnormalities, except FBG.

Several studies have suggested that mHealth is a good alternative to the conventional clinical management of cardiometabolic disease risk factors, mainly as a result of its accessibility and usefulness to healthcare providers and customers alike $[34,35]$. Although participants, study periods, and the information and methods presented on apps have differed across studies, behavioral changes have nevertheless been found to lead to improvements in health outcomes, including body weight, BP, and cholesterol [14]. In a study that consisted of 99 Israeli adults, IG, in which they received, over a period of 14 weeks, real-time performance feedback concerning exercise and diet through a web-based app, diet quality score, and physical activity significantly increased; and body weight and body mass index (BMI) significantly decreased in IG compared with the control group [36]. Further, in Stuckey et al. [37], a small-scale study involving 26 Canadian adults with metabolic abnormalities, it was found that after eight weeks the IG's amount of exercise increased while BMI, BP, and cholesterol levels decreased The members of the IG performed self-monitoring using data from BP monitors, glucometers, and a pedometer featured on an app and, based on this information, received tailored counseling at 4-week intervals [37]. In another study involving young Austrian adults, an IG that received information once a week using four apps (one for each behavior), showed an increase in dietary habits and exercise and a decrease in weight and BMl after 12 weeks, compared to the control group [38]. Another study showed that when information is provided less frequently and over a period of six months, the IG maintains a reduced body weight, but does not present any significant changes in terms of health behaviors [39]. Therefore, it can be speculated that motivation to practice healthy behaviors increases with the frequency with which tailored information is provided, which consequently improves health outcomes.

On the other hand, some studies found mHealth interventions not to be effective [40]. For instance, a study that examined 51 young Australian adults aged 18-35 years over 12 weeks found that using a mobile app did not lead to significant differences in diet, exercise, BP, or weight in comparison to the control group [40]. Similarly, a study on 90 Irish individuals aged 
16 years or older reported that the average number of steps increased, but weight and BP remained unchanged [41]. Personalization and adaptation in real time are important factors for engaging various users [42], and it could be speculated that studies that did not find significant effects might not have used individualized information, had low engagement [40], or had a study period that was too short to observe improvements in health outcomes [41].

Generally, app usage is known to markedly decrease within the first number of weeks [43,44]; although our study could not analyze app usage, the service was launched for 1,000 people, and 911 people continued to use the app until week 24. This suggests a longer average period of use than that shown in other studies. The higher persistence of app utilization in our study might have resulted not only from allowing the participants to perform self-management through the mobile app throughout the 24 weeks, but also from the automated management featured in the app. Automated management included weekly reports concerning health information, monthly exercise, and nutritional consultations. Other factors that may have encouraged continued use of the app include: the monthly health practice reports, the compensation (incentive) system for promoting persistent use, and tailored analysis and consultations with experts at the public health center. Incentives were provided throughout the study with rewards (mobile gift cards) given monthly for excellent users (top 10\%) and souvenirs given for people who completed the 24-week program. In the future, studies should be conducted to investigate whether the altered behaviors and health outcomes observed in this study are maintained over the long-term or are further improved. In addition, although the ideal protocol for mHealth monitoring is yet to be established, developing more sophisticated and diverse mobile app programs that can provide immediate feedback would be more effective for managing cardiometabolic risks for both medical professionals and patients.

After adjusting for factors that showed significant effects, it was found that the factors that significantly improved more than one health risk factor were: the female gender, moderate physical activity, vegetable intake at every meal, low sodium in food, and reducing grease or fats in food, respectively.

Recent findings on app technologies suggest that women and younger age groups use mobile apps more frequently $[45,46]$; in our study, age was not a significant factor, but considering that risk decreased 1.37 times more in women than in men, we can speculate that women used and accepted the app more than the men.

Next, according to a meta-analysis of cohort studies, metabolic syndrome risk decreases with increased physical activity $[47,48]$. This is believed to be because physical activity reduces abdominal obesity, which in turn reduces metabolic risks; this has been substantiated in some previous trials $[49,50]$. Recent public health guidelines [51,52] recommend individuals engage in at least 150 minutes of moderate physical activity or 75 minutes of vigorous physical activity per week in order to maintain good health. Despite evaluating in this study a lower amount of physical activity than public health guidelines recommend as sufficient, health risk factors decreased 1.61 times more for members of the mHealth IG than for those in the conventional IG. Nevertheless, to lower additional metabolic syndrome risks, strategies to increase moderate physical activity are needed.

Our findings concerning dietary practice are supported by the current evidence that suggests that daily intake of fruits and vegetables can lower cardiometabolic risks [53]. The rich reserve of potassium in fruits and vegetables lowers BP [54], while fiber helps to reduce risks of obesity and overweight by increasing feelings of fullness [55]; further, fiber also lowers BP [56] and regulates insulin [57]. In our study, eating fruit did not significantly lower risk factors; however, eating two types of vegetables at every meal lowered risks by 1.27 times. After the intervention, there were more people who began to eat an appropriate amount of vegetables than eat an appropriate amount of fruits, which may be attributable to the higher accessibility of vegetables due to their cheaper costs [58]. Research has suggested that a healthy diet that is low in fat and salt/sodium may help to prevent cardiovascular disease $[59,60]$ Due to the characteristics of Korean food culture, Koreans tend to consume high amounts of salt [59,61], and the consumption of meats, which contain a relatively high amount of saturated fatty acids and are recommended to be consumed only in small quantities, is gradually increasing in the country $[60,61]$. In our study, not adding salt or soy sauce to food during consumption and removing the fats in meats before eating lowered metabolic risks by 1.65 times and 1.77 times, respectively. These 2 lifestyle habits might have made the highest contributions to lowering metabolic risks in this study because they are relatively easier to practice at every meal, requiring no altering of cooking methods or amount of intake.

There were some limitations to our study. First, this was not a randomized controlled trial. Randomization was not possible because this study aimed to investigate the effects of mHealth services in regard to improving metabolic abnormalities, using data from three public health centers as part of a national project. Nevertheless, this feature of our study may be beneficial, as our study protocol can be used to expand the entire national project. Second, this study only presents results for adults who visited public health centers and who completed the intervention, so the findings cannot be generalized to less-motivated adults. Third, we could not analyze whether behaviors and metabolic risks differ in relation to the amount of app usage. Fourth, changes in dietary and exercise habits were assessed using questionnaires, but because respondents tend to lean toward better outcomes on self-reported questionnaires [62], the effects of the intervention in improving health behaviors may have been overestimated. Fifth, the proportions of sex that may have effect on the difference of other demographic factors were different between the two groups, but we did not stratify men and women in order to have enough statistical power.

Despite the above, to the best of our knowledge our study is the first to prove that mHealth services are effective for managing metabolic risks in public health center settings, as opposed to hospital settings, in Korea. In general, people who can monitor their health problems accept health information more readily because they feel more obliged, and are more willing, to alter their health behaviors [63]. This study was performed on individuals without disease but who had health 
risk factors, and we expect the effects of the intervention to be greater on people with diseases, such as diabetes, hypertension, hyperlipidemia, and cardiovascular diseases.

The findings of this study suggest that the additional use of community-based mHealth services via a mobile app is an effective method of improving health behaviors and lowering metabolic risks in Koreans. In particular, our finding that mHealth intervention improves metabolic risks by promoting changes in health knowledge and behaviors, such as dietary habits and exercise, in local communities is meaningful. Efforts to optimize the smartphone app as well as the conducting of randomized controlled clinical trials with a larger sample are needed in the future.

\section{CONFLICT OF INTEREST}

The authors declare no potential conflicts of interests.

\section{ORCID}

Tae-Yon Kim: https://orcid.org/0000-0001-6745-2552

Yun-Su Lee: https://orcid.org/0000-0002-7935-8376

Eun-Jung Yu: https://orcid.org/0000-0003-1878-1995

Min-Su Kim: https://orcid.org/0000-0003-3624-1757

Sun-Young Yang: https://orcid.org/0000-0001-6660-1632

Yang-Im Hur: https://orcid.org/0000-0002-2633-9980

Jae-Heon Kang: https://orcid.org/0000-0002-5209-0824

\section{REFERENCES}

1. World Health Organization. Global status report on noncommunicable diseases 2014 [Internet]. Geneva: World Health Organization; 2014 [cited 2017 December 5]. Available from: http://www.who.int/nmh/ publications/ncd-status-report-2014/en/.

2. Knowler WC, Barrett-Connor E, Fowler SE, Hamman RF, Lachin JM, Walker EA, Nathan DM; Diabetes Prevention Program Research Group. Reduction in the incidence of type 2 diabetes with lifestyle intervention or metformin. N Engl J Med 2002;346:393-403.

3. National Cholesterol Education Program (NCEP) Expert Panel on Detection, Evaluation, and Treatment of High Blood Cholesterol in Adults (Adult Treatment Panel III). Third report of the National Cholesterol Education Program (NCEP) expert panel on detection, evaluation, and treatment of high blood cholesterol in adults (adult treatment panel III) final report. Circulation 2002;106:3143-421.

4. Cardiometabolic Risk Working Group: Executive Committee, Leiter LA, Fitchett DH, Gilbert RE, Gupta M, Mancini GB, McFarlane PA, Ross R, Teoh H, Verma S, Anand S, Camelon K, Chow CM, Cox JL, Després JP, Genest J, Harris SB, Lau DC, Lewanczuk R, Liu PP, Lonn EM, McPherson R, Poirier P, Qaadri S, Rabasa-Lhoret R, Rabkin SW, Sharma AM, Steele AW, Stone JA, Tardif JC, Tobe S, Ur E. Cardiometabolic risk in Canada: a detailed analysis and position paper by the cardiometabolic risk working group. Can J Cardiol 2011;27:e1-33.

5. Huffman KM, Sun JL, Thomas L, Bales CW, Califf RM, Yates T, Davies MJ, Holman RR, McMurray JJ, Bethel MA, Tuomilehto J, Haffner SM, Kraus WE. Impact of baseline physical activity and diet behavior on metabolic syndrome in a pharmaceutical trial: results from NAVIGATOR. Metabolism 2014;63:554-61.

6. World Health Organization. Adherence to long-term therapies: evidence for action 2013 [Internet]. Geneva: World Health Organization; 2003 [cited 2017 December 5]. Available from: http://www.who. int/chp/knowledge/publications/adherence_report/en/.

7. Murdock A, Rodgers C, Lindsay H, Tham TC. Why do patients not keep their appointments? Prospective study in a gastroenterology outpatient clinic. J R Soc Med 2002;95:284-6.

8. Paterson BL, Charlton P, Richard S. Non-attendance in chronic disease clinics: a matter of non-compliance? J Nurs Healthc Chronic IIIn 2010;2:63-74.

9. Oh B, Cho B, Han MK, Choi $\mathrm{H}$, Lee MN, Kang HC, Lee $\mathrm{CH}$, Yun $\mathrm{H}$, Kim Y. The effectiveness of mobile phone-based care for weight control in metabolic syndrome patients: randomized controlled trial. JMIR Mhealth Uhealth 2015;3:e83.

10. Riley WT, Rivera DE, Atienza AA, Nilsen W, Allison SM, Mermelstein R. Health behavior models in the age of mobile interventions: are our theories up to the task? Transl Behav Med 2011;1:53-71.

11. Payne HE, Lister C, West JH, Bernhardt JM. Behavioral functionality of mobile apps in health interventions: a systematic review of the literature. JMIR Mhealth Uhealth 2015;3:e20.

12. World Health Organization. mHealth: new horizons for health through mobile technologies [Internet]. Geneva: World Health Organization; 2011 [cited 2017 December 5]. Available from: http://www.who.int/ goe/publications/goe_mhealth_web.pdf.

13. Patrick K, Griswold WG, Raab F, Intille SS. Health and the mobile phone. Am J Prev Med 2008;35:177-81.

14. Schoeppe S, Alley S, Van Lippevelde W, Bray NA, Williams SL, Duncan MJ, Vandelanotte C. Efficacy of interventions that use apps to improve diet, physical activity and sedentary behaviour: a systematic review. Int J Behav Nutr Phys Act 2016;13:127.

15. Piette JD, List J, Rana GK, Townsend W, Striplin D, Heisler M. Mobile health devices as tools for worldwide cardiovascular risk reduction and disease management. Circulation 2015;132:2012-27.

16. Norman GJ, Kolodziejczyk JK, Adams MA, Patrick K, Marshall SJ. Fruit and vegetable intake and eating behaviors mediate the effect of a randomized text-message based weight loss program. Prev Med 2013;56:3-7.

17. Park MJ, Kim HS. Evaluation of mobile phone and Internet intervention on waist circumference and blood pressure in post-menopausal women with abdominal obesity. Int J Med Inform 2012;81:388-94.

18. Liang X, Wang Q, Yang X, Cao J, Chen J, Mo X, Huang J, Wang $L, G u$ D. Effect of mobile phone intervention for diabetes on glycaemic control: a meta-analysis. Diabet Med 2011;28:455-63.

19. Logan AG, Irvine MJ, Mclsaac WJ, Tisler A, Rossos PG, Easty A, Feig DS, Cafazzo JA. Effect of home blood pressure telemonitoring with self-care support on uncontrolled systolic hypertension in diabetics. Hypertension 2012;60:51-7.

20. Park LG, Howie-Esquivel J, Chung ML, Dracup K. A text messaging intervention to promote medication adherence for patients with coronary heart disease: a randomized controlled trial. Patient Educ Couns 2014;94:261-8.

21. Cowdery J, Majeske P, Frank R, Brown D. Exergame apps and physical activity: the results of the ZOMBIE trial. Am J Health Educ 2015;46:216-22.

22. Gasser R, Brodbeck D, Degen M, Luthiger J, Wyss R, Reichlinal S. Persuasiveness of a mobile lifestyle coaching application using social facilitation. In: IJsselsteijn WA, de Kort YAW, Midden C, Eggen $B$, van den Hoven $E$, editors. Persuasive Technology. PERSUASIVE 
2006. Lecture Notes in Computer Science, vol 3962. Berlin/Heidelberg: Springer; 2006. p.27-38.

23. Wharton $\mathrm{CM}$, Johnston $\mathrm{CS}$, Cunningham BK, Sterner D. Dietary self-monitoring, but not dietary quality, improves with use of smartphone app technology in an 8-week weight loss trial. J Nutr Educ Behav 2014;46:440-4.

24. Wigginton C, Curran M, Brodeur C. Global Mobile Consumer Trends. 2nd ed. New York (NY): Deloitte Touche Tohmatsu Ltd.; 2017.

25. Song TM, Ryu S, Lee SH. U-health service for managing chronic disease: a case study on managing metabolic syndrome in a health center in South Korea. Healthc Inform Res 2011;17:260-6.

26. Joo NS, Kim BT. Mobile phone short message service messaging for behaviour modification in a community-based weight control programme in Korea. J Telemed Telecare 2007;13:416-20.

27. Alberti KG, Zimmet P, Shaw J; IDF Epidemiology Task Force Consensus Group. The metabolic syndrome--a new worldwide definition. Lancet 2005;366:1059-62.

28. Lee SY, Park HS, Kim DJ, Han JH, Kim SM, Cho GJ, Kim DY, Kwon HS, Kim SR, Lee CB, Oh SJ, Park CY, Yoo HJ. Appropriate waist circumference cutoff points for central obesity in Korean adults. Diabetes Res Clin Pract 2007;75:72-80.

29. Ministry of Health and Welfare, Korea Health Promotion Institute. One-Stop Health service Consultation Manual. Seoul: Korea Health Promotion Institute; 2011.

30. Ministry of Health and Welfare, Korea Health Promotion Institute. Health Exam Result Consultation Manual - Nutritional Consultation. Seoul: Korea Health Promotion Institute; 2012.

31. McKay FH, Cheng C, Wright A, Shill J, Stephens H, Uccellini M. Evaluating mobile phone applications for health behaviour change: a systematic review. J Telemed Telecare 2018;24:22-30.

32. Kelly JT, Reidlinger DP, Hoffmann TC, Campbell KL. Telehealth methods to deliver dietary interventions in adults with chronic disease: a systematic review and meta-analysis. Am J Clin Nutr 2016;104:1693-702.

33. Ezzati M, Riboli E. Behavioral and dietary risk factors for noncommunicable diseases. N Engl J Med 2013;369:954-64.

34. Logan AG. Transforming hypertension management using mobile health technology for telemonitoring and self-care support. Can J Cardiol 2013;29:579-85.

35. Weinstein RS, Lopez AM, Joseph BA, Erps KA, Holcomb M, Barker GP, Krupinski EA. Telemedicine, telehealth, and mobile health applications that work: opportunities and barriers. Am J Med 2014;127:183-7.

36. Safran Naimark J, Madar Z, Shahar DR. The impact of a web-based app (eBalance) in promoting healthy lifestyles: randomized controlled trial. J Med Internet Res 2015;17:e56.

37. Stuckey M, Russell-Minda E, Read E, Munoz C, Shoemaker K, Kleinstiver P, Petrella R. Diabetes and Technology for Increased Activity (DaTA) study: results of a remote monitoring intervention for prevention of metabolic syndrome. J Diabetes Sci Technol 2011;5:928-35.

38. Partridge SR, McGeechan K, Hebden L, Balestracci K, Wong AT, Denney-Wilson E, Harris MF, Phongsavan P, Bauman A, AllmanFarinelli $M$. Effectiveness of a mHealth lifestyle program with telephone support (TXT2BFiT) to prevent unhealthy weight gain in young adults: Randomized controlled trial. JMIR Mhealth Uhealth 2015;3:e66.

39. Allman-Farinelli $M$, Partridge SR, McGeechan $K$, Balestracci $K$,
Hebden L, Wong A, Phongsavan P, Denney-Wilson E, Harris MF, Bauman A. A mobile health lifestyle program for prevention of weight gain in young adults (TXT2BFiT): Nine-month outcomes of a randomized controlled trial. JMIR Mhealth Uhealth 2016;4:e78.

40. Hebden L, Cook A, van der Ploeg HP, King L, Bauman A, AllmanFarinelli M. A mobile health intervention for weight management among young adults: a pilot randomised controlled trial. J Hum Nutr Diet 2014;27:322-32.

41. Glynn LG, Hayes PS, Casey M, Glynn F, Alvarez-Iglesias A, Newell J, OLaighin G, Heaney D, O'Donnell M, Murphy AW. Effectiveness of a smartphone application to promote physical activity in primary care: the SMART MOVE randomised controlled trial. Br J Gen Pract 2014;64:e384-91.

42. Spring B, Gotsis M, Paiva A, Spruijt-Metz D. Healthy apps: mobile devices for continuous monitoring and intervention. IEEE Pulse 2013;4:34-40.

43. Davies CA, Spence JC, Vandelanotte C, Caperchione CM, Mummery WK. Meta-analysis of internet-delivered interventions to increase physical activity levels. Int J Behav Nutr Phys Act 2012;9:52.

44. Dennison L, Morrison L, Conway G, Yardley L. Opportunities and challenges for smartphone applications in supporting health behavior change: qualitative study. J Med Internet Res 2013;15:e86.

45. Guertler D, Vandelanotte C, Kirwan M, Duncan MJ. Engagement and nonusage attrition with a free physical activity promotion program: the case of 10,000 steps Australia. J Med Internet Res 2015;17:e176.

46. Sandholzer M, Deutsch T, Frese T, Winter A. Predictors of students self-reported adoption of a smartphone application for medical education in general practice. BMC Med Educ 2015;15:91.

47. He D, Xi B, Xue J, Huai P, Zhang M, Li J. Association between leisure time physical activity and metabolic syndrome: a meta-analysis of prospective cohort studies. Endocrine 2014;46:231-40.

48. Zhang D, Liu X, Liu Y, Sun X, Wang B, Ren Y, Zhao Y, Zhou J, Han C, Yin L, Zhao J, Shi Y, Zhang M, Hu D. Leisure-time physical activity and incident metabolic syndrome: a systematic review and doseresponse meta-analysis of cohort studies. Metabolism 2017;75:36-44.

49. McTiernan A, Sorensen B, Irwin ML, Morgan A, Yasui $Y$, Rudolph RE, Surawicz C, Lampe JW, Lampe PD, Ayub K, Potter JD. Exercise effect on weight and body fat in men and women. Obesity (Silver Spring) 2007;15:1496-512.

50. Trapp EG, Chisholm DJ, Freund J, Boutcher SH. The effects of high-intensity intermittent exercise training on fat loss and fasting insulin levels of young women. Int J Obes 2008;32:684-91.

51. Garber CE, Blissmer B, Deschenes MR, Franklin BA, Lamonte MJ, Lee IM, Nieman DC, Swain DP; American College of Sports Medicine. American College of Sports Medicine position stand. Quantity and quality of exercise for developing and maintaining cardiorespiratory musculoskeletal, and neuromotor fitness in apparently healthy adults: guidance for prescribing exercise. Med Sci Sports Exerc 2011;43:1334-59.

52. Department of Health, Social Services and Public Safety; The Scottish Governmnet; Llywodraeth Cymru Welsh Government; Department of Health (GB). Start active, stay active: a report on physical activity for health from the four home countries' Chief Medical Officers [Internet]. London: Department of Health; 2011 [cited 2017 December 5]. Available from: www.gov.uk/government/uploads/ system/uploads/attachment_data/file/216370/dh_128210.pdf.

53. Boeing $H$, Bechthold $A$, Bub $A$, Ellinger $S$, Haller $D$, Kroke $A$, Leschik-Bonnet $E$, Müller $M J$, Oberritter $H$, Schulze $M$, Stehle $P$, Watz 
B. Critical review: vegetables and fruit in the prevention of chronic diseases. Eur J Nutr 2012;51:637-63.

54. Aburto NJ, Hanson S, Gutierrez H, Hooper L, Elliott P, Cappuccio FP. Effect of increased potassium intake on cardiovascular risk factors and disease: systematic review and meta-analyses. BMJ 2013;346:f1378.

55. Streppel MT, Arends LR, van 't Veer P, Grobbee DE, Geleijnse JM. Dietary fiber and blood pressure: a meta-analysis of randomized placebo-controlled trials. Arch Intern Med 2005;165:150-6.

56. Wanders AJ, van den Borne JJ, de Graaf $C$, Hulshof $T$, Jonathan MC, Kristensen M, Mars M, Schols HA, Feskens EJ. Effects of dietary fibre on subjective appetite, energy intake and body weight: a systematic review of randomized controlled trials. Obes Rev 2011 12:724-39.

57. Weickert MO, Pfeiffer AF. Metabolic effects of dietary fiber consumption and prevention of diabetes. J Nutr 2008;138:439-42.

58. Cobiac $\amalg$, Vos T, Veerman JL. Cost-effectiveness of interventions to promote fruit and vegetable consumption. PLoS One 2010;5: e14148.

59. Oh $\mathrm{H}$, Lee HY, Jun DW, Lee SM. Low salt diet and insulin resistance. Clin Nutr Res 2016;5:1-6.

60. Zock PL, Blom WA, Nettleton JA, Hornstra G. Progressing insights into the role of dietary fats in the prevention of cardiovascular disease. Curr Cardiol Rep 2016;18:111.
61. Ministry of Health and Welfare, Korea Centers for Disease Control and Prevention. National Health Survey 1998; 2001 National Health and Nutrition Survey; The Third Korea National Health and Nutrition Examination Survey (KNHANES III), 2005; Korea Health Statistics 2007: Korea National Health and Nutrition Examination Survey (KNHANES IV-1); Korea Health Statistics 2008: Korea National Health and Nutrition Examination Survey (KNHANES IV-2); Korea Health Statistics 2009: Korea National Health and Nutrition Examination Survey (KNHANES IV-3); Korea Health Statistics 2010: Korea National Health and Nutrition Examination Survey (KNHANES V-1); Korea Health Statistics 2011: Korea National Health and Nutrition Examination Survey (KNHANES V-2); Korea Health Statistics 2012: Korea National Health and Nutrition Examination Survey (KNHANES V-3). Cheongwon: Korea Centers for Disease Control and Prevention; c1999-2013.

62. Lichtman SW, Pisarska K, Berman ER, Pestone $M$, Dowling $H$, Offenbacher E, Weisel H, Heshka S, Matthews DE, Heymsfield SB. Discrepancy between self-reported and actual caloric intake and exercise in obese subjects. N Engl J Med 1992;327:1893-8.

63. Pietersma S, Dijkstra A. Do behavioural health intentions engender health behaviour change? A study on the moderating role of self-affirmation on actual fruit intake versus vegetable intake. $\mathrm{Br}$ J Health Psychol 2011;16:815-27. 